\title{
Comments on 'Gait Disturbance Due to Foot Drop Is Refractory to Treatment in Nonsystemic Vasculitic Neuropathy'
}

\author{
Michael P. Collins ${ }^{a}$ Robert D.M. Hadden ${ }^{b}$ \\ ${ }^{a}$ Medical College of Wisconsin, Milwaukee, Wisc., USA; ${ }^{\mathrm{b}}$ King's College Hospital, London, UK
}

Dear Sir,

The article by Hirahara et al. describes retrospective observations on 16 patients with nonsystemic vasculitic neuropathy (NSVN) [1]. NSVN is a rare disorder with only eight series reporting clinical information on more than ten patients [2,3]. A Peripheral Nerve Society (PNS) task force published a guideline on NSVN in 2010 [2]. As members of this task force, we have questions about this study.

How did the authors distinguish between 'polyneuropathy' and 'mononeuritis multiplex?' How were diffuse polyneuropathies with asymmetric features categorized?

How many patients had pain? In table 1, only three had 'myalgias', but another three presented with lower limb pain.

Were electrodiagnostic findings axonal or demyelinating?

Two patients had 'eruption' as their first symptom. Cutaneous vasculitis excludes NSVN, which can be diagnosed only in the absence of extra-neurologic clinical involvement (pathologic involvement in muscle biopsy permitted).
Patient 13 had an erythrocyte sedimentation rate of $115 \mathrm{~mm} / \mathrm{h}$, exceeding the PNS guideline cutoff of $100 \mathrm{~mm} / \mathrm{h}$ for NSVN. This patient should be presumed to have a systemic vasculitic neuropathy.

In table 1, the 'diameter of artery with angiitis' ranges from $75-600 \mu \mathrm{m}$ (mean 270 $\mu \mathrm{m})$. In five patients, affected arteries were 400-600 $\mu \mathrm{m}$. For the 11 patients with 'probable' vasculitis, that is, no vessel exhibiting inflammatory vessel-wall damage, there would be no pathologic basis on which to ascertain the size of angiitisaffected vessels [2]. How did the authors determine the size of the involved vessels in these patients? Moreover, the tabulated vessel sizes are unexpectedly large. Almost all vessels in sural nerve biopsies are $\leq 300$ $\mu \mathrm{m}[4]$. In the two previous analyses of affected vessel size in NSVN, mean diameters were $98 \pm 87 \mu \mathrm{m}$ and $80 \pm 31 \mu \mathrm{m}[5,6]$. Can the authors explain these inconsistencies?

What was the duration between the initial' and 'final' modified Rankin scale (mRS) assessment for each patient?
The final $\mathrm{mRS}$ for patients $6,7,8$, and 14 is inconsistent between tables 1 and 2 . According to table 1 , three of sixteen patients improved; according to table 2 , five of twelve patients improved. Both response rates are lower than those reported in past studies, where most patients improved with immunosuppressive therapy [7-9]. This cohort might have done worse due to the reliance on corticosteroid monotherapy and under-treatment with the gold standard for severe small-vessel vasculitis, cyclophosphamide.

The title of this paper is misleading. The gait disturbance is likely due not only to foot drop but also sensory loss and plantar flexion weakness. Was the foot drop bilateral or unilateral? Foot drop is an indicator of the severity of a neuropathy; its refractoriness is usually relative and not absolute.

We appreciate the authors' interest in this underreported disorder and applaud their pioneering work in identifying prognostic factors for NSVN.

\section{KARGER 125}

(C) 2014 S. Karger AG, Base

$0014-3022 / 14 / 0732-0078 \$ 39.50 / 0$
Michael P. Collins, MD

Department of Neurology, Medical College of Wisconsin

9200 West Wisconsin Avenue

Milwaukee, WI 53226 (USA)

E-Mail periquet1@yahoo.com 


\section{References}

1 Hirahara T, Yamashita S, Misumi Y, Kawakami K, Hori H, Honda S, Watanabe M, Ikeda T, Yamashita T, Maeda Y, Ando Y: Gait disturbance due to foot drop is refractory to treatment in nonsystemic vasculitic neuropathy. Eur Neurol 2014;71:180-186.

2 Collins MP, Dyck PJ, Gronseth GS, Guillevin L, Hadden RD, Heuss D, Léger JM, Notermans NC, Pollard JD, Said G, Sobue G, Vrancken AF, Kissel JT; Peripheral Nerve Society: Peripheral Nerve Society Guideline on the classification, diagnosis, investigation, and immunosuppressive therapy of non-systemic vasculitic neuropathy: executive summary. J Peripher Nerv Syst 2010;15:176-184.
3 Agadi JB, Raghav G, Mahadevan A, Shankar SK: Usefulness of superficial peroneal nerve/ peroneus brevis muscle biopsy in the diagnosis of vasculitic neuropathy. J Clin Neurosci 2012;19:1392-1396.

4 Midroni G, Bilbao JM: Biopsy diagnosis of peripheral neuropathy. Boston, ButterworthHeinemann, 1995, p 106.

5 Sugiura M, Koike H, Iijima M, Mori K, Hattori N, Katsuno M, Tanaka F, Sobue G: Clinicopathologic features of nonsystemic vasculitic neuropathy and microscopic polyangiitis-associated neuropathy: a comparative study. J Neurol Sci 2006;241:31-37.
-6 Kararizou E, Davaki P, Karandreas N, Davou R, Vassilopoulos D: Nonsystemic vasculitic neuropathy: a clinicopathological study of 22 cases. J Rheumatol 2005;32:853-858.

7 Davies L, Spies JM, Pollard JD, McLeod JG: Vasculitis confined to peripheral nerves. Brain 1996;119:1441-1448.

8 Collins MP, Periquet MI, Mendell JR, Sahenk Z, Nagaraja HN, Kissel JT: Nonsystemic vasculitic neuropathy: insights from a clinical cohort. Neurology 2003;61:623-630.

$\checkmark 9$ Mathew L, Talbot K, Love S, Puvanarajah S, Donaghy M: Treatment of vasculitic peripheral neuropathy: a retrospective analysis of outcome. QJM 2007;100:41-51. 